\title{
Mannitol Treatment in Experimental Haemophilus influenzae Type b Meningitis ${ }^{1}$
}

\author{
GEORGE A. SYROGIANNOPOULOS, KURT D. OLSEN, AND GEORGE H. MCCRACKEN, JR. \\ Department of Pediatrics, The University of Texas Health Science Center at Dallas, Southwestern Medical
} School, Dallas, Texas 75235

\begin{abstract}
A study was undertaken to evaluate hypertonic mannitol treatment in experimental lapin Haemophilus influenzae type b meningitis and to compare these results with those in normal rabbits. Increased intracranial pressure, brain water content, and concentrations of lactate and hypoxanthine in cerebrospinal fluid (CSF) were measured as a reflection of altered cerebral perfusion and hypoxia and potential brain injury associated with meningitis. A single dose of mannitol reduced transiently the CSF pressure of uninfected rabbits from $2.15 \pm 0.20$ to $1.34 \pm$ $0.10 \mathrm{~mm} \mathrm{Hg}$ (maximum reduction $34.9 \pm 8.4 \% ; p<0.005$ ). The time to the lowest pressure was $38.7 \pm 2.7 \mathrm{~min}$ after initiation of the infusion and the time to return of CSF pressure to initial values was $76.7 \pm 5.6 \mathrm{~min}$. In infected mannitol-treated animals the CSF pressure was reduced from $4.78 \pm 0.53$ to $2.61 \pm 0.55 \mathrm{~mm} \mathrm{Hg}$ (maximum reduction $42.0 \pm 7.7 \% ; p<0.005$ ). Time to maximum pressure decrease was $44.0 \pm 5.6 \mathrm{~min}$. CSF pressure returned to the initial level after $178.5 \pm 25.2 \mathrm{~min}$. Four $h$ after initiation of mannitol infusion the mean brain water content in infected mannitol-treated animals was $412 \pm 4$ $\mathrm{g} \mathrm{H}_{2} \mathrm{O} / 100 \mathrm{~g}$ dry weight and in infected untreated animals it was $415 \pm 3 \mathrm{~g} \mathrm{H}_{2} \mathrm{O} / 100 \mathrm{~g}$ dry weight $(p>0.05)$. CSF lactate and hypoxanthine concentrations were significantly increased during the $20 \mathrm{~h}$ of meningeal inflammation $(p<$ 0.005 ). The mean percentage change from baseline values for lactate concentrations at the end of the experiment (24 h) in infected mannitol-treated rabbits was significantly smaller than that in infected untreated animals $(p=0.035)$. A single dose of mannitol reduced the CSF hypoxanthine concentrations of infected animals, but this reduction was not statistically significant. (Pediatr Res 22: 118-122, 1987)
\end{abstract}

\section{Abbreviations}

cfu, colony-forming units

$\mathrm{CMRO}_{2}$, cerebral metabolic rate of oxygen

CSF, cerebrospinal fluid

WBC, white blood cells

LDH, lactate dehydrogenase

HPLC, high-pressure liquid chromatography

Meningitis caused by Haemophilus influenzae is associated with a case-fatality rate of approximately $5 \%$ and with neurological sequelae in about $30 \%$ of survivors (1). The advent of more

Received October 24, 1986; accepted February 19, 1987

Correspondence Dr. George A. Syrogiannopoulos, Department of Pediatrics, University of Patras, School of Medicine, Patras, Greece.

${ }^{1}$ Presented in part at the 25th Interscience Conference on Antimicrobial Agents and Chemotherapy, Minneapolis, MN, September 29-October 2, 1985. potent antimicrobial agents is unlikely to improve significantly the outcome from Haemophilus meningitis (2-5) and only little progress has been made in elucidating the mechanisms that contribute to brain damage in patients with meningitis. Brain edema, increased intracranial pressure, and the diminished cerebral blood flow have been considered important factors in the pathogenesis of the brain injury (6-8).

The present study was undertaken to evaluate hypertonic mannitol treatment in experimental lapin $H$. influenzae type b meningitis and to compare these results with those in normal animals. Increased intracranial pressure, brain water content, and brain lactate and hypoxanthine production, the latter being reflected by concentrations of lactate and hypoxanthine in CSF, were assessed as a reflection of altered cerebral perfusion and hypoxia and potential brain injury associated with meningitis.

\section{METHODS}

Animal model. A model of experimental meningitis originally described by Dacey and Sande (9) was used in a modified form (10). New Zealand White male rabbits $(2-3 \mathrm{~kg})$ were used.

Anesthesia. Anesthesia was induced using pentobarbital 20 $\mathrm{mg} / \mathrm{kg}$ intravenously for all experimental procedures. In the case that a continuous recording of CSF pressure was required, steady anesthesia was maintained by means of a constant iv infusion of pentobarbital $5 \mathrm{mg} / \mathrm{kg} / \mathrm{h}$, which was started $60 \mathrm{~min}$ after the initial dose of pentobarbital. Preliminary studies carried out in normal uninfected animals showed that with the above regimen, CSF pressure was steady over a period of $4 \mathrm{~h}$ with a coefficient of variation of $9 \%$

Production of meningitis. The anesthetized animals were immobilized in a stereotactic frame. A spinal needle (31/2 in, 20 gauge) was introduced into the cisterna magna.

Meningitis was induced by intracisternal injection of $0.2 \mathrm{ml}$ of an inoculum of $10^{8}-10^{9} \mathrm{cfu}$ of $H$. influenzae type $\mathrm{b} / \mathrm{ml}$, originally isolated from the CSF of an infant with meningitis. The organism produced $\beta$-lactamase.

The same procedure of immobilization and cisternal puncture, which was performed at the beginning of the experiment $\left(T_{0}\right)$, was repeated at 20 and $24 \mathrm{~h}$ after induction of meningitis, to measure intracisternal pressure and to obtain CSF for WBC count, number of bacterial cells, and lactate and hypoxanthine concentrations. All experiments took place at a room temperature of 18.3 to $21.1^{\circ} \mathrm{C}$.

Treatment. Twenty $\mathrm{h}$ after induction of infection rabbits received either no therapy or $25 \%$ mannitol given as a $1 \mathrm{~g} / \mathrm{kg}$ dose by constant intravenous infusion in $20 \mathrm{~min}$. Additionally six uninfected control animals received the same regimen of mannitol.

Enumeration of WBC and bacteria in CSF. CSF WBC were counted in a Neubaur hematocytometer. The number of bacteria in CSF was quantified by preparing 10 -fold dilutions and inoc- 
ulating chocolate agar plates, which were incubated for $16 \mathrm{~h}$ at $37^{\circ} \mathrm{C}$ in $5 \% \mathrm{CO}_{2}$.

CSF lactate and hypoxanthine measurements. The CSF specimens were centrifuged in a microcentrifuge for 1 min within 30 $\mathrm{s}$ of collection. The supernatant was stored immediately at $-70^{\circ}$ C. Samples were analyzed at various intervals after collection and storage.

Lactate was measured by a kinetic enzymatic method, which utilized the reaction of lactate with $\beta-\mathrm{NAD}^{+}$in the presence of LDH to produce NADH and pyruvate (11). The NADH production was quantitatively monitored at $340 \mathrm{~nm}$ absorbance on a 2600 Gilford spectrophotometer utilizing a UV deterium source. Precision of the method was assessed by testing a known standard of $40 \mathrm{mg}$ of lactate/dl (no. 826-10, Sigma Chem. Co., St. Louis, MO) 10 times during the course of one day. The coefficient of variation was $2.2 \%$.

Hypoxanthine concentrations were measured by HPLC (12) using a Waters liquid chromatograph (Waters Associates, Inc., Milford, MA), equipped with a high-pressure delivery pump (M$45)$ and a variable-wave length detector (M-450) set at $254 \mathrm{~nm}$. Separation was achieved with a reverse-phase Techsphere-C18 column [particle size, $5 \mu \mathrm{m} ; 25 \mathrm{~cm}$ (length) by $4.6 \mathrm{~mm}$ (inside diameter); Chromanetics Corp., Kensington, MD]. The mobile phase contained $0.02 \mathrm{M} \mathrm{KH}_{4} \mathrm{PO}_{4}$ buffer solution, pH to 3.0 with phosphoric acid (degassed and filtered before each analysis). Hypoxanthine standards were prepared in HPLC mobile phase solution to a concentration range of 0.5 to $20 \mu \mathrm{M} /$ liter. Hypoxanthine was well separated from endogenous CSF compounds with retention time of $6.5 \mathrm{~min}$. CSF samples were prepared for HPLC by filtration through Millex-HV $\mathrm{HV}_{4}$ filter units $(0.45 \mu \mathrm{m}$ pore size, Millipore Corp., Bedford, MA).

Identification of hypoxanthine was confirmed by enzymatic degradation of the hypoxanthine peak through catalysis with xanthine oxidase to produce xanthine, which has a different peak retention time. Precision of the method was evaluated by measuring a $10 \mu \mathrm{M} /$ liter standard extracted and analyzed 10 times in the course of a day. The coefficient of variation was $2.4 \%$.

All specimens collected from individual rabbits were assayed at the same time. Because of the relatively large interassay variability, the percentage change rather than the absolute differences from baseline values was considered to be a more appropriate parameter for comparison purposes.

Intracisternal pressure measurement. Intracisternal pressure was measured at $\mathrm{T}_{\mathrm{o}}$ and 20 and $24 \mathrm{~h}$ later. After initiation of mannitol therapy at $20 \mathrm{~h}$ a continuous recording of cerebrospinal pressure was obtained until the end of the experiment at $24 \mathrm{~h}$. As soon as free flow was established through the spinal needle, and before removing or adding fluid, the spinal needle was connected with a water-filled mechanical pressure transducer (Gould Statham P 23 ID; Gould Inc., Oxnard, CA). The pressure was recorded on a multichannel polygraph (R611 Dynograph Recorder; Beckman Instruments Inc., Schiller Park, IL). The transducer was referenced to the level of the cisterna magna, while the animal was lying in a prone position. The CSF pressure was obtained by electronic integration of the respective transducer signals. Before each measurement the transducer was calibrated with a mercury manometer. Measurements of pressure were considered accurate when 1) average pressure was stable for $15 \mathrm{~s}, 2)$ respiration was associated with measurable change in pressure, and 3) compression of the jugular vein induced elevation of pressure. Intracisternal pressure is expressed in $\mathrm{mm} \mathrm{Hg}$ $\left(1 \mathrm{~mm} \mathrm{Hg}=13.6 \mathrm{~mm} \mathrm{H}_{2} \mathrm{O}\right.$ ).

Brain water content measurement. A standard procedure for the estimation of brain edema was used. This involves sampling brain tissue $(10,13,14)$ and expressing the respective brain water content as $\mathrm{g}$ of water per $100 \mathrm{~g}$ of dry weight $(10,14)$. The brain water content was calculated employing the formula:

$$
\text { brain water content }=\frac{\text { wet weight }- \text { dry weight }}{\text { dry weight }} \times 100
$$

At the end of the experiment (i.e. $24 \mathrm{~h}$ ) the animals were sacrificed by an overdose $(150 \mathrm{mg} /$ animal $)$ of pentobarbital given intravenously. Immediately after death a craniotomy was performed and the brain without the cerebellum and medulla was removed and weighed in glass dishes. The brain was then dried to stable weight (approximately $1 \mathrm{wk}$ ) in a vacuum oven (Precision Scientific Group, Chicago, IL) at a temperature of $105^{\circ} \mathrm{C}$ and a vacuum of $-50 \mathrm{KPa}$. For comparison purposes, 18 rabbits without meningitis were sacrificed and brain water content measured.

Statistical analysis. Values are expressed as mean \pm 1 SEM. Comparison of a single parameter between two groups was performed by two-tailed Student's $t$ test. Animals were compared within a treatment group using one way repeated measures analysis of variance followed by Student-Neuman-Keuls pairwise multiple comparisons (15). A $p$ value $<0.05$ was considered significant.

\section{RESULTS}

At $20 \mathrm{~h}$ the infected rabbits were febrile $\left(\geq 39.5^{\circ} \mathrm{C}\right)$ and lethargic or comatose. The mean bacterial counts were $3.4 \pm 0.2$ and $3.8 \pm 0.2 \log _{10} \mathrm{cfu} / \mathrm{ml}$ at $20 \mathrm{~h}$, and $3.9 \pm 0.3$ and $4.2 \pm 0.3$ $\log _{10} \mathrm{cfu} / \mathrm{ml}$ at $24 \mathrm{~h}$ in the mannitol-treated and untreated infected animals, respectively (Table 1).

Cerebrospinal fluid WBC counts, expressed in $10^{3}$ cells $/ \mu \mathrm{l}$, were $6.1 \pm 1.7$ and $9.6 \pm 2.4$ at $20 \mathrm{~h}(p>0.05$ between the two groups) and $5.7 \pm 1.6$ and $9.1 \pm 2.0$ at $24 \mathrm{~h}(p>0.05$ between the two groups) in the mannitol-treated and untreated infected animals, respectively.

In the uninfected animals (control group) the CSF remained sterile throughout the experiment and no CSF pleocytosis was noted.

CSF pressure. Twenty hours after initiation of the experiment there was a significant increase in CSF pressure in the two groups of infected animals $(p<0.005$; Table 2$)$. By contrast, there were no significant changes in CSF pressure in the uninfected rabbits.

A single dose of mannitol reduced transiently the CSF pressure of uninfected rabbits (Fig. 1). The maximum reduction in CSF pressure was $34.9 \pm 8.4 \%$. The intracisternal pressure was reduced from $2.15 \pm 0.20$ to $1.34 \pm 0.10 \mathrm{~mm} \mathrm{Hg}(p<0.005)$. The time to the lowest pressure was $38.7 \pm 2.7 \mathrm{~min}$ after initiation of the infusion and the time to return of CSF pressure to initial values was $76.7 \pm 5.6 \mathrm{~min}$.

In infected animals with increased CSF pressure, a transient further increase in CSF pressure was recorded during the infusion of mannitol in all but one animal (Fig. 1). This was followed by a maximum reduction in CSF pressure of $42.0 \pm 7.7 \%$. The intracisternal pressure was reduced from $4.78 \pm 0.53$ to $2.61 \pm$ $0.55 \mathrm{~mm} \mathrm{Hg}(p<0.005)$. Time to maximum pressure decrease was $44.0 \pm 5.6 \mathrm{~min}$. CSF pressure returned to the initial level after $178.5 \pm 25.2 \mathrm{~min}$.

A rebound increase in intracranial pressure following mannitol treatment was not recorded in any of the treated animals.

Table 1. CSF bacterial counts in rabbits with $H$. influenzae type $b$ meningitis

Mean \pm 1 SEM no. bacteria as $\log _{10}$ $\mathrm{cfu} / \mathrm{ml}$

\begin{tabular}{llcc} 
Group & $0 \mathrm{H}$ & $20 \mathrm{H}$ & $24 \mathrm{H}$ \\
\cline { 2 - 4 } $\begin{array}{l}\text { I. Uninfected rabbits } \\
\text { treated } \dagger\end{array}$ & $\mathrm{ND}^{*}$ & Sterile & Sterile \\
$\begin{array}{l}\text { II. Infected rabbits treated } \dagger \\
\text { III. Infected rabbits untreated }\end{array}$ & $\mathrm{ND}$ & $3.4 \pm 0.2(12) \ddagger$ & $3.9 \pm 0.3(12)$ \\
$\mathrm{ND}$ & $3.8 \pm 0.2(9)$ & $4.2 \pm 0.3(9)$ \\
\hline
\end{tabular}

* Not determined.

$\dagger 20$-min intravenous infusion of $25 \%$ mannitol given to groups I and II.

$\ddagger$ Numbers in parentheses represents number of animals. 
Table 2. Effect of mannitol* therapy on CSF pressure in experimental $H$. influenzae type $b$ meningitis

\begin{tabular}{clcc}
\hline & \multicolumn{3}{c}{ Mean \pm 1 SEM CSF pressure in mm Hg $(n)$} \\
\cline { 2 - 4 } Group & $0 \mathrm{H}$ & $20 \mathrm{H}$ & $24 \mathrm{H}$ \\
\hline I. Uninfected rabbits treated* & $2.28 \pm 0.24(6)$ & $2.15 \pm 0.20(6)$ & $2.12 \pm 0.34(6)$ \\
II. Infected rabbits treated* & $2.02 \pm 0.33(11)$ & $4.78 \pm 0.53(1) \dagger$ & $5.11 \pm 0.71(11)$ \\
III. Infected rabbits untreated & $2.00 \pm 0.29(10)$ & $5.13 \pm 0.59(10) \dagger$ & $5.49 \pm 0.87(10)$ \\
\hline
\end{tabular}

* 20 -min intravenous infusion of $25 \%$ mannitol given to groups I and II.

$\dagger p<0.005$ in comparison with preinfection values.

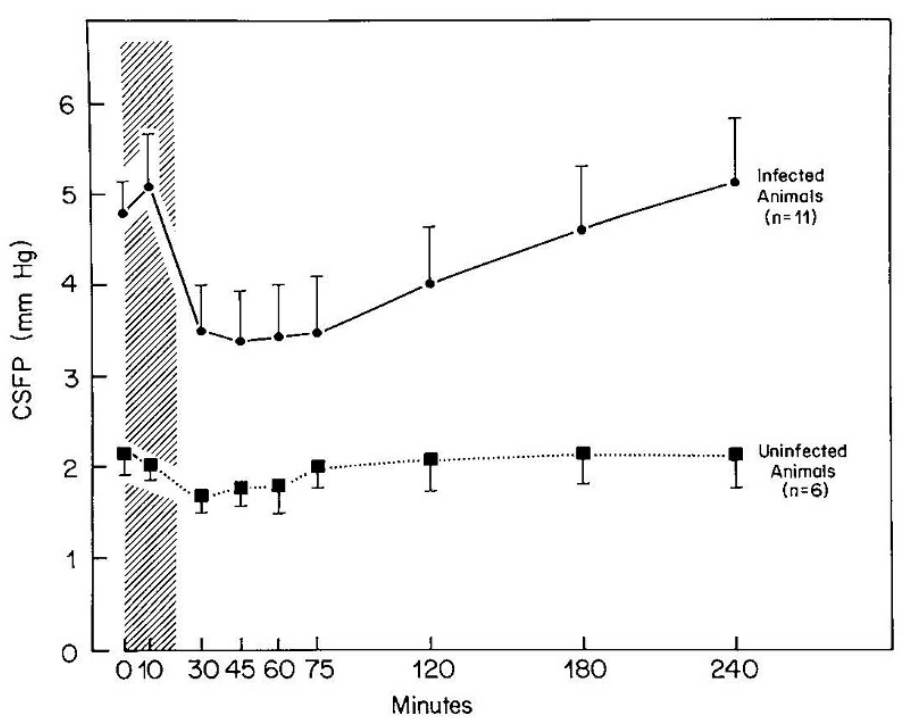

Fig. 1. Mean CSF pressure ( \pm 1 SEM) at various times following mannitol infusion in infected and uninfected rabbits. The time that the maximum pressure occured and the total time that CSF pressure remained at significantly reduced levels varied considerably from animal to animal. See text for the mean \pm 1 SEM of the lowest achieved pressures in each group. The cross-hatched vertical column represents the infusion time of $20 \mathrm{~min}$.

At the end of the experiment $(24 \mathrm{~h}) \mathrm{CSF}$ pressure in mannitoltreated infected animals returned to values similar to untreated infected animals (Table 2). At $24 \mathrm{~h}$ normal uninfected animals had CSF pressure comparable to baseline $\left(\mathrm{T}_{\mathrm{o}}\right)$ values.

CSF lactate and hypoxanthine concentrations. At $20 \mathrm{~h}$ after the beginning of the experiment, CSF lactate concentrations were significantly increased ( $p<0.005$; Fig. 2$)$, in the two groups of infected animals. At $24 \mathrm{~h}$ CSF lactate concentrations were significantly reduced from these at $20 \mathrm{~h}$ in the infected rabbits treated with mannitol whereas the values were somewhat increased in untreated infected animals.

CSF hypoxanthine concentrations were significantly elevated at $20 \mathrm{~h}$ of infection ( $p<0.005$; Fig. 3$)$. At $24 \mathrm{~h}$ mannitol-treated infected animals had reduced CSF hypoxanthine concentrations compared with values at $20 \mathrm{~h}$ but this reduction was not statistically significant.

Brain water content. At completion of the experiments (24 h) the brain water content of infected animals was similar in both mannitol-treated $\left(412 \pm 4 \mathrm{~g} \mathrm{H}_{2} \mathrm{O}\right) / 100 \mathrm{~g}$ dry weight) and untreated $\left(415 \pm 3 \mathrm{~g} \mathrm{H}_{2} \mathrm{O} / 100 \mathrm{~g}\right.$ dry weight $)$ animals. Those values were substantially elevated compared with values of uninfected, mannitol-treated animals at $24 \mathrm{~h}\left(402 \pm 6 \mathrm{~g} \mathrm{H}_{2} \mathrm{O} / 100 \mathrm{~g}\right.$ dry weight) and of uninfected nontreated animals $\left(405 \pm 3 \mathrm{~g} \mathrm{H}_{2} \mathrm{O}\right.$ / $100 \mathrm{~g}$ dry weight).

\section{DISCUSSION}

In 1961, Wise and Chater (16) first used mannitol for treatment of brain edema and increased intracranial pressure. Although

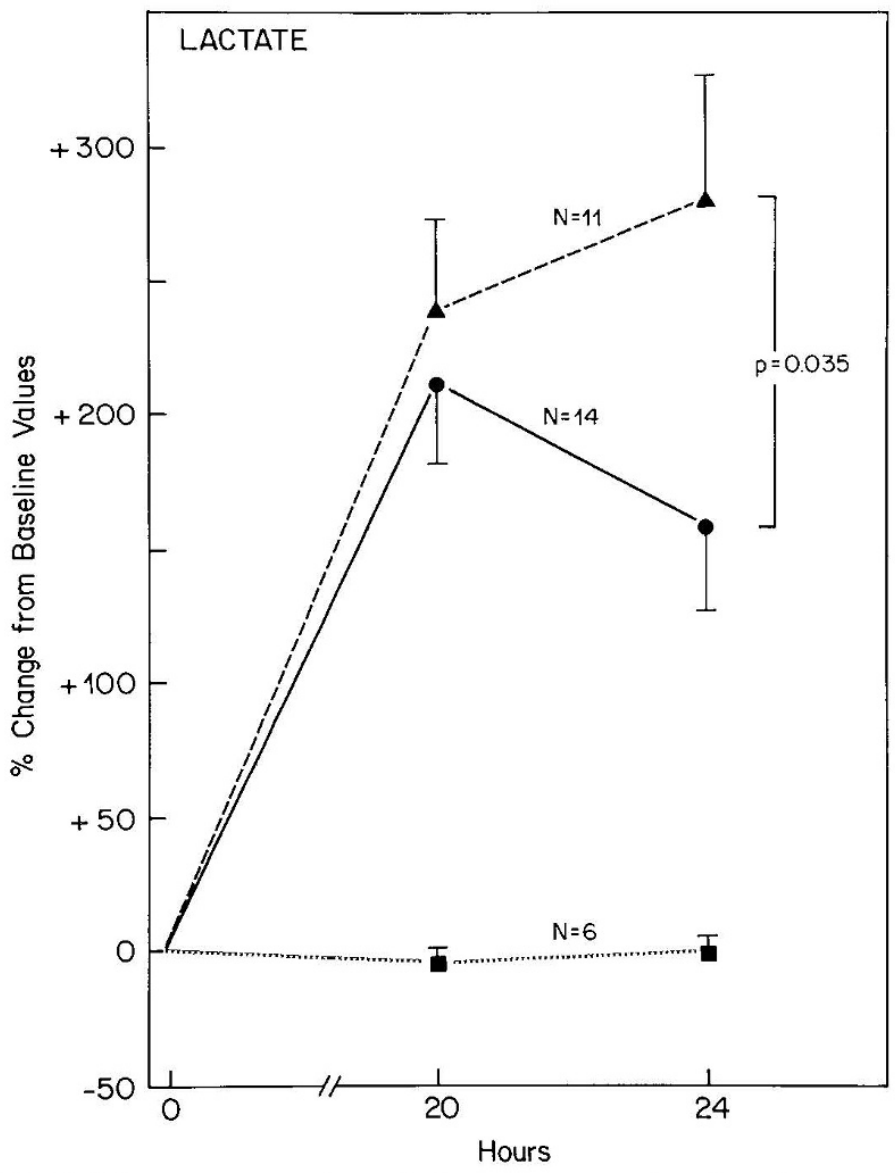

Fig. 2. Mean percentage change in lactate concentrations from baseline values ( \pm 1 SEM) at 20 and $24 \mathrm{~h}$ after the initiation of the experiment. Twenty-min intravenous infusion of $25 \%$ mannitol was administered at $20 \mathrm{~h}$. Infected rabbits-mannitol treated $(\boldsymbol{\bullet})$; infected rabbits-untreated $(\mathbf{\Lambda})$; uninfected rabbits treated( $\mathbf{\square})$.

there is extensive experience with use of mannitol in neurosurgical patients with mass lesions (17-20) and in patients with cerebral edema postsurgery or secondary to head trauma $(19,21$, 22) or cerebral ischemia (19), use of mannitol in patients with bacterial meningitis has been principally empirical. There is also limited experience with another osmotic agent, urea, in the treatment of bacterial meningitis. Hypertonic urea was administered intravenously to six children with $H$. influenzae meningitis (23). Following urea treatment a prompt neurological improvement occurred in four of the six patients. This improvement was presumably related to a reduction in intracranial pressure although this was not specifically measured.

Brain edema in bacterial meningitis has features of vasogenic, cytotoxic, and interstitial (hydrocephalic) cerebral edema (2426). Mannitol is considered to have its effect mainly on the vasogenic and cytotoxic forms of edema (25). Mannitol therapy significantly reduced brain edema in patients with brain tumors (20), in cytotoxic edema produced by 6-aminonicotinamide in 


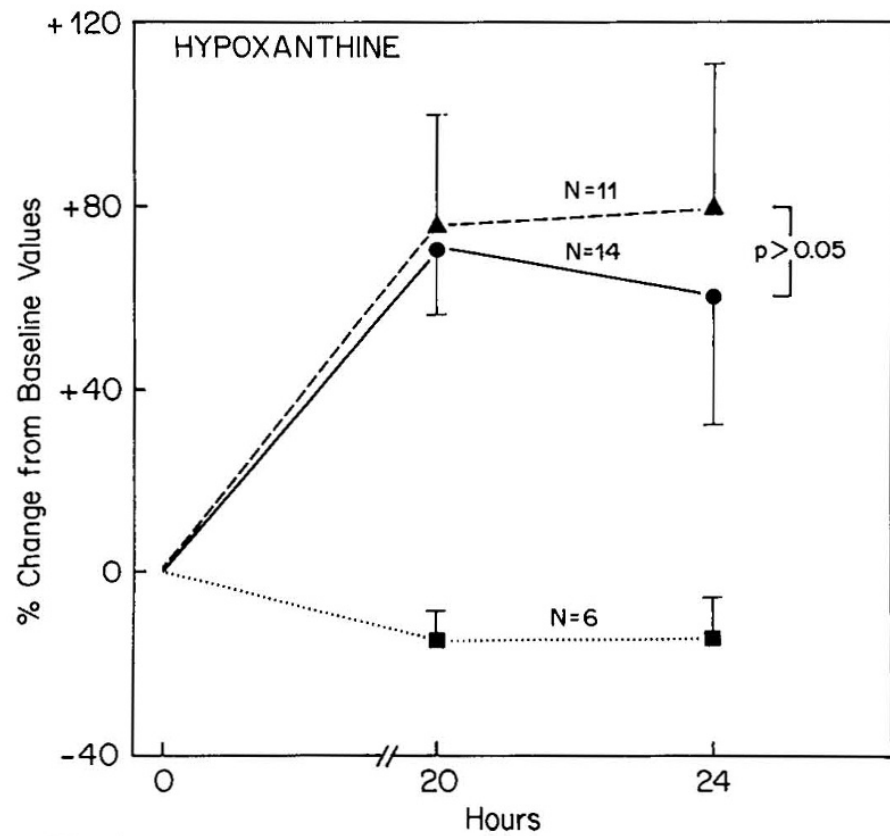

Fig. 3. Mean percentage change in hypoxanthine concentrations from baseline values ( \pm 1 SEM) at 20 and $24 \mathrm{~h}$ after initiation of the experiment. Twenty-min intravenous infusion of $25 \%$ mannitol was administered at $20 \mathrm{~h}$. Infected rabbits-mannitol treated (O); infected rabbits-untreated $(\boldsymbol{\Delta})$; uninfected rabbits treated $(\boldsymbol{\square})$.

rabbits (27), and in cryogenic lesion in dogs (28). In those studies the brain water content was measured either by using CT density assessment $(20,28)$ or by weighing brain samples $(27,28)$ within $1 \mathrm{~h}$ from the initiation of mannitol infusion. Harbaugh et al. (29) found that mannitol did not significantly reduce the edematous tissue in cryogenic lesions in rabbits despite the fact that the brain water content was measured during the time of maximal reduction of intracranial pressure.

We did not find a significant reduction in brain water content in animals treated with mannitol compared with values in untreated animals. This observation is possibly attributed to the fact that the brain water content was measured $3 \mathrm{~h}$ and $40 \mathrm{~min}$ after completion of the mannitol infusion, at a time when CSF pressure had returned to pretreatment values.

In all animals mannitol consistently reduced intracisternal pressure. Factors modulating the response to mannitol include the dose and duration of mannitol infusion, the frequency of the doses $(30)$, and the underlying central nervous system process for which therapy is given. The maximal reduction in CSF pressure recorded by other investigators has been from $27 \%$ (31) to $107.8 \%$ (29). An accurate dose-response relation in different clinical situations has not been well defined (32).

The initial increase in CSF pressure after beginning mannitol therapy was observed only in the infected rabbits and was most likely caused by an increase in cardiac output (stroke volume) with a resultant increase in cerebral blood flow $(31-37)$. The increased cerebral blood flow is associated with a concomitant reduction in cerebrovascular resistance and a change in $\mathrm{CMRO}_{2}$.

Improvement of cerebral blood flow might be a beneficial effect of mannitol treatment in acute bacterial meningitis because it is known that cerebral blood flow is diminished during meningitis $(38,39)$. In animals with cerebral ischemia, administration of mannitol resulted in improvement of cerebral blood flow and in protection from further ischemic changes $(40,41)$. Furthermore, it has been proposed that mannitol may protect against or improve ischemia by acting as a free radical scavenger (42). Oxygen-derived free radicals induce cellular injury to the brain and cause edema as well as changes in vascular permeability (4345).
Brain edema and increased intracranial pressure with decreased perfusion can cause abnormal cerebral metabolism. Increased lactate is presumed to be a product of brain tissue hypoxia $(39,46)$. At the same time brain tissue hypoxia leads to increased ATP breakdown, products of which are hypoxanthine, xanthine, and inosine (47-50).

The concentrations of lactate that were increased at $20 \mathrm{~h}$ after induction of $H$. influenzae meningitis were significantly reduced after the 20 -min infusion of mannitol (at $24 \mathrm{~h}$ ). It is possible that this finding can be attributed to improved intracranial hemodynamics, increased cerebral perfusion, and increased oxygen availability to the brain tissue, resulting in improved glucose utilization. A significant reduction of CSF lactate concentrations after one 20 -min infusion of mannitol is surprising considering that diminution in CSF lactate concentrations in CNS infections after initiation of appropriate treatment is known to be slow. A single dose of mannitol reduced the CSF hypoxanthine concentrations of infected animals, but this reduction was not statistically significant. This may not necessarily be related to persistent increased hypoxanthine production by the brain tissue, but may represent delayed clearance of hypoxanthine from CSF. Mannitol had no effect on the WBC or on the bacterial counts in CSF.

\section{CONCLUSION}

A single dose of hypertonic mannitol reduced transiently the CSF pressure in all animals, especially those with experimental meningitis caused by $H$. influenzae type $\mathrm{b}$. Although the mean brain water content of mannitol-treated animals $220 \mathrm{~min}$ after completion of mannitol therapy was similar to that of untreated animals, CSF lactate concentrations in infected animals were significantly reduced after treatment. The latter finding might be a result of improved cerebral blood flow and restoration of aerobic cerebral glucose metabolism.

It is not possible to apply directly results from these animal studies to patients with Haemophilus meningitis. Because meningeal inflammation and edema can result in reduced cerebral perfusion pressure in children with meningitis, additional studies in humans should be undertaken in order to assess different therapeutic modalities that might modulate the effects of the cerebral inflammatory reaction and improve blood flow and eventual outcome.

Acknowledgment. The authors thank Dr. Joan S. Reisch of the Medical Computing Resources Center for assistance in the statistical analysis of the data.

\section{REFERENCES}

1. Ferry PC, Culbertson JL, Cooper JA, Sitton AB, Sell SHW 1982 Sequelae of Haemophilus influenzae meningitis: preliminary report of a long-term follow-up study. In: Sell SH, Wright PF (eds) Haemophilus influenzae. Epidemiology, Immunology and Prevention of Disease. Elsevier Biomedical Press, New York, pp 111-117

2. del Rio MA. Chrane D, Shelton S, McCracken GH Jr, Nelson JD 1983 Ceftriaxone versus ampicillin and chloramphenicol for treatment of bacterial meningitis in children. Lancet 1:1241-1244

3. Kaplan SL, Mason EO, Mason SK, Catlin FI, Lee RT, Murphy M, Feigin RD 1984 Prospective comparative trial of moxalactam versus ampicillin or chloramphenicol for treatment of Haemophilus influenzae type b meningitis in children. J Pediatr 104:447-453

4. Jacobs RF, Wells TG, Steele RW, Yamauchi T 1985 A prospective randomized comparison of cefotaxime vs ampicillin and chloramphenicol for bacteria meningitis in children. J Pediatr 107:129-133

5. Odio CM, Faingezicht I, Salas JL, Guevara J, Mohs E, McCracken GH Jr 1986 Cefotaxime versus conventional therapy for the treatment of bacterial meningitis of infants and children. Pediatr Infect Dis 5:402-407

6. Dodge PR, Swartz MN 1965 Bacterial meningitis-a review of selected aspects. II. Special neurologic problems, postmeningitic complications and clinicopathological correlations. N Engl J Med 272:954-960

7. Goiten KJ, Tamir I 1983 Cerebral perfusion pressure in central nervous system infections of infancy and childhood. J Pediatr 103:40-43

8. McMenamin JB, Volpe JJ 1984 Bacterial meningitis in infancy: effects on intracranial pressure and cerebral blood flow velocity. Neurology (Cleveland) 34:500-504

9. Dacey RG, Sande MA 1974 Effect of probenecid on cerebrospinal fluid 
concentrations of penicillin and cephalosporin derivatives. Antimicrob Agents Chemother 6:437-441

10. Tauber MG, Khayam-Bashi H, Sande MA 1985 Effects of ampicillin and corticosteroids on brain water content, cerebrospinal fluid pressure and cerebrospinal fluid lactate levels in experimental pneumococcal meningitis. J Infect Dis 151:528-534

11. Papanastasiou-Diamandi A, Siskos PA, Diamandis EP 1983 A direct kinetic fluorimetric method for the enzymatic determination of lactate in plasma. Clin Chim Acta 129:359-364

12. Boulieu R, Bory C, Baltassat P, Gonnet C 1984 Simultaneous determination of allopurinol, oxipurinol, hypoxanthine and xanthine in biological fluids by high-performance liquid chromatography. J Chromatogr 307:469-474

13. Chan PH, Longar S, Fishman RA 1983 Phospholipid degradation and edema development in cold-injured rat brain. Brain Res 277:329-337

14. Syrogiannopoulos GA, Olsen KD, Reisch JS, McCracken GH Jr 1987 Dexamethasone in the treatment of experimental Haemophilus influenzae type b meningitis. J Infect Dis 155:213-219

15. Zar JH 1984 Biostatistical Analysis, 2nd ed. Prentice-Hall, Inc., Englewood Cliffs, NJ

16. Wise BL, Chater N 1961 Effect of mannitol on cerebrospinal fluid pressure. The actions of hypertonic mannitol solutions and of urea compared. Arch Neurol 4:200-202

17. Shenkin HA, Goluboff B, Haft H 1962 The use of mannitol for the reduction of intracranial pressure in intracranial surgery. J Neurosurg 19:897-900

18. Wise BL, Chater N 1962 The value of hypertonic mannitol solution in decreasing brain mass and lowering cerebrospinal-fluid pressure. J Neurosurg 19:1038-1043

19. Miller JD, Leech P 1975 Effects of mannitol and steroid therapy on intracranial volume-pressure relationships in patients. J Neurosurg 42:274-281

20. Cascino T, Baglivo J, Conti J, Szewczykowski J, Posner JB, Rottenberg DA 1983 Quantitative CT assessment of furosemide-and mannitol-induced changes in brain water content. Neurology (Cleveland) 33:898-903

21. McGraw CP, Howard G 1983 Effect of mannitol on increased intracranial pressure. Neurosurgery 13:269-271

22. Muizelaar JP, Lutz HA, III, Becker DP 1984 Effect of mannitol on ICP and $\mathrm{CBF}$ and correlation with pressure autoregulation in severely head-injured patients. J Neurosurg 61:700-706

23. Williams CPS, Swanson AG, Chapman JT 1964 Brain swelling with acute purulent meningitis. Report of treatment with hypertonic intravenous urea. Pediatrics 34:220-227

24. Prockop LD, Fishman RA 1968 Experimental pneumococcal meningitis. Permeability changes influencing the concentration of sugars and macromolecules in cerebrospinal fluid. Arch Neurol 19:449-463

25. Fishman RA 1975 Brain edema. N Engl J Med 293:706-711

26. Fishman RA, Sligar K, Hake RB 1977 Effects of leukocytes on brain metabolism in granulocytic brain edema. Ann Neurol 2:89-94

27. James HE, Bruce DA, Welsh F 1978 Cytotoxic edema produced by 6-Aminonicotinamide and its response to therapy. Neurosurgery 3:196-200

28. Albright AL, Latchaw RE, Robinson AG 1984 Intracranial and systemic effects of osmotic and oncotic therapy in experimental cerebral edema. J Neurosurg 60:481-489

29. Harbaugh RD, James HE, Marshall LF, Shapiro HM, Laurin R 1979 Acute therapeutic modalities for experimental vasogenic edema. Neurosurgery 5:656-665

30. McGraw CP, Alexander E Jr, Howard G 1978 Effect of dose and dose schedule on the response of intracranial pressure to mannitol. Surg Neurol 10:127130
31. Wilkinson HA, Rosenfeld S 1983 Furosemide and mannitol in the treatment of acute experimental intracranial hypertension. Neurosurgery 12:405-410

32. Fishman RA 1980 Cerebrospinal Fluid in Diseases of the Nervous System WB Saunders, Philadelphia, pp 124-126

33. Goluboff B, Shenkin HA, Haft H 1964 The effects of mannitol and urea on cerebral hemodynamics and cerebrospinal fluid pressure. Neurology 14:891898

34. Johnston IH, Harper AM 1973 The effect of mannitol on cerebral blood flow. An experimental study. $J$ Neurosurg 38:46l-471

35. Kassell NF, Baumann KW, Hitchon PW, Gerk MK, Hill TR, Sokoll MD 1981 Influence of a continuous high dose infusion of mannitol on cerebral blood flow in normal dogs. Neurosurgery 9:283-286

36. Dempsey RJ, Kindt GW 1982 Experimental augmentation of cerebral blood flow by mannitol in epidural intracranial masses. J Trauma 22:449-454

37. Ravussin P, Archer DP, Tyler JL, Meyer E, Abou-Madi M, Diksic M, Yamamoto L, Trop D 1986 Effects of rapid mannitol infusion on cerebral blood volume. A position emission tomographic study in dogs and man. $J$ Neurosurg 64:104-113

38. Paulson OB, Brodersen P, Hansen EL, Kristensen HS 1974 Regional cerebra blood flow, cerebral metabolic rate of oxygen and cerebrospinal fluid acidbase variables in patients with acute meningitis and with acute encephalitis. Acta Med Scand 196:191-198

39. Smith AL, Daum RS, Scheifele D, Syriopoulou V, Averill DR, Roberts MC, Stull TL 1982 Pathogenesis of Haemophilus influenzae meningitis. In: Sell SH, Wright PF (eds) Haemophilus influenzae. Epidemiology, Immunology and Prevention of Disease. Elsevier Biomedical Press, New York, pp 89-109

40. Cantu RC, Ames A III 1969 Experimental prevention of cerebral vasculature obstruction produced by ischemia. J Neurosurg 30:50-54

41. Little JR 1979 Treatment of acute focal cerebral ischemia with intermittent, low dose mannitol. Neurosurgery 5:687-691

42. Mizoi K, Yoshimoto T, Suzuki J 1981 Experimental study of new cerebral protective substances-functional recovery of severe, incomplete ischaemic brain lesions pretreated with mannitol and fluorocarbon emulsion. Acta Neurochirur 56:157-166

43. Chan PH, Fishman RA 1980 Transient formation of superoxide radicals in polyunsaturated fatty acid-induced brain swelling. J Neurochem 35:10041007

44. Chan PH, Yurko M, Fishman RA 1982 Phospholipid degradation and cellular edema induced by free radicals in brain cortical slices. J Neurochem 38:525531

45. Chan PH, Schmidley JW, Fishman RA, Longar SM 1984 Brain injury, edema, and vascular permeability changes induced by oxygen-derived free radicals. Neurology 34:315-320

46. Rutledge J, Benjamin D, Hood L, Smith A 1981 Is the CSF lactate measurement useful in the management of children with suspected bacterial meningitis? J Pediatr 98:20-24

47. Saugstad OD, Schrader H, Aasen AO 1976 Alteration of the hypoxanthine level in cerebrospinal fluid as an indicator of tissue hypoxia. Brain Res 112:188-189

48. Meberg A, Saugstad OD 1978 Hypoxanthine in cerebrospinal fluid in children. Scand J Clin Lab Invest 38:437-440

49. Bejar R, Saugstad OD, James H, Gluck L 1983 Increased hypoxanthine concentrations in cerebrospinal fluid of infants with hydrocephalus. J Pediatr 103:44-48

50. Harkness RA, Lund RJ 1983 Cerebrospinal fluid concentrations of hypoxanthine, xanthine, uridine and inosine: high concentrations of the ATP metabolite, hypoxanthine, after hypoxia. J Clin Pathol 36:1-8 